AVANT, Vol. XII, No. 2

ISSN: 2082-6710 avant.edu.pl/en

DOI: 10.26913/avant. 2021.02.02

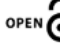

\% Access 2 îs

\title{
Boundaries of Stigma. Anti-Stigma Campaigns as Social Control and a Source of Self-Stigma
}

\author{
Radosław Stupak \\ Faculty of Philosophy, Jagiellonian University \\ radek.stupak@doctoral.uj.edu.pl
}

Received 19 December 2020; accepted 10 October 2021; published 2 November 2021.

\begin{abstract}
The article presents stigma in mental health as a boundary object for different scientific disciplines. The research that is dominated by the approaches present in medicine and quantitative social sciences has resulted in the conceptualizations of stigma and practical solutions to combat it that seem counter-effective. It has also neglected important questions about the role of stigma in society. It is argued that biomedical understanding of mental distress is inherently stigmatizing and anti-stigma campaigns based on this discourse are necessarily paradoxical and lead to self-stigma. This could be interpreted along the lines of Foucault's concepts of biopower, panopticon and governmentality. Another perspective could emerge from utilizing concepts associated with the Frankfurt School, especially Lukacs's reification and Adorno's identity thinking. Anti-stigma campaigns can be seen as a means of social control, legitimizing the use of stigmatizing labels and the biomedical psychiatric discourse that ultimately serve to preserve the social, cultural and economic status-quo.
\end{abstract}

Keywords: stigma; self-stigma; critical psychiatry; critical theory; Frankfurt School

\section{Introduction}

Research and clinical practice in mental health is, for many reasons, an interesting case of boundaries in science. Addressing just one of several boundaries at stake, it could be argued that clinical psychology has been colonized by the medical (or psychiatric) approach and, probably in order to maintain the status of a "serious science", willfully adopted the methods and solutions of psychiatry (Deacon, 2013). In this essay I will try to briefly outline how the biomedical concept of mental illness can serve as a means for population control via the construct of stigma, and how psychiatry could be seen to play a similar role to that of eugenics as described by Rose (1979). In order to do this, I will first very briefly describe the concepts of 
stigma and self-stigma (going back to Goffman's account) and then try to address them critically, pointing out the paradoxes inherent in anti-stigma campaigns that rely on the biomedical model of mental distress. To this end, I will refer mainly to some empirical research, Foucault's concept of biopower and Hacking's dynamic nominalism. I will then try to argue that utilizing the concepts of scholars associated with the Frankfurt School (especially Lukacs and Adorno, also Honneth) could be helpful in developing the critique further and perhaps fostering social change, a possibility that seems to have been largely overlooked so far.

\section{Stigma}

There is a lot of debate surrounding the issues of stigmatization and self-stigmatization in relation to mental health and the problem is often portrayed as one of the most important factors hindering recovery. The very concept of recovery is problematic in itself (Bellack, 2006), but it seems that even less critical attention has been given to the concepts of stigmatization and especially self-stigmatization.

Goffman (1963) is widely considered to be the most important contributor to the study of social stigma, if not its "founding father". He describes stigma as "an attribute that is deeply discrediting" reducing people "from a whole and usual person to a tainted, discounted one" with a "spoiled identity" (p. 3). Ahmedani (2011) adds that in the social work literature stigma has been defined as "stereotypes or negative views attributed to a person or groups of people when their characteristics or behaviors are viewed as different from or inferior to societal norms", a definition which is clearly influenced by the standpoint of cognitive social psychology.

Tyler and Slater (2018) rightly notice that this individualistic approach, along with the use of micro-sociological and/or psychological research leads to omitting or sidelining crucial "questions about where stigma is produced, by whom and for what purposes." They argue that there were four important points made by Goffman: "that stigma is a perspective which is 'generated in social contexts'; second, that people learn to manage the potentially devastating effects of being socially stigmatised, by employing strategies of identity management, such as passing and concealment; third, and this remains more implicit in Goffman's account, that stigmatisation is historically specific in the forms it takes; and finally, that stigma functions 'as a means of formal social control'." (p. 721)

According to them, research, policy-making and anti-stigma initiatives have been dominated by the first of these two claims, while the third and fourth have become marginalized or completely omitted.

The attempts to better understand and combat stigma have been mostly made by medical researchers and professions adopting quantitative methods in order to measure, classify and quantify stigma as a static phenomenon. On the other hand, conceptualizations derived from social psychology that focus on mental processes and their interpersonal consequences lead to interventions aimed at changing attitudes or behaviors of individuals by increasing "tolerance" or changing the "perception" of disorders. This approach "often ignores the ways in which, 
for example, governments or corporations might deliberately activate stigma to 'nudge' people into desired patterns of behaviour." (Tyler \& Slater, 2018, p. 732)

Stigma is then a boundary object (as defined by Good (2000), i.e. a concept studied by researchers representing different disciplines, e.g. "self", "identity", "culture")) for psychiatry, sociology, social psychology, and clinical psychology. There have been various criticisms of the concept of stigma (Link \& Phelan, 2001), but as I will try to show later, it should also be addressed from a much broader perspective.

\section{Self-stigma}

Bathje and Marston (2014) claim that self-stigmatization is a component of the broader social phenomenon known as stigmatization and that it exists within the context of public stigma. They provide an often used definition of self-stigma as "the process in which a person with a mental health diagnosis becomes aware of public stigma, agrees with those stereotypes, and internalizes them by applying them to the self." (pp. 1714).

While this shows that it is impossible to think about self-stigma without the wider context of stigma itself, another of their remarks hints at a much more important problem, namely that most of the research on self-stigma treats it as a barrier to seeking help from the mental health care system that most often takes the form of therapy or medication. They note: "there is often an assumption that avoidance of treatment services is related to fear of stigmatization, it is also important to recognize that mental health service providers sometimes contribute to stigmatization.” (Bathje \& Marston, 2014, p. 1714)

"Sometimes contribute" seems to be a gross understatement, and this becomes especially evident if one goes back to Goffman's earlier work presented in Asylums (1961). The book is concerned with psychiatric hospitals as total institutions, but even if we take the optimistic stance that the realities and practices of mental health care are more humane today than in the times of Goffman, the argument as a whole stands: the goal of the institution - understood not necessarily as a total one like an asylum, but also as mental health services in general, even if provided in the community - is to remodel the patient's identity (and, accordingly, behavior) so that it fits the notions provided by the institution. In order for the patient to submit to the authority and the bureaucratic regime of the institution, a host of direct and indirect interventions are used, so that the patient accepts the label and the role associated with it. As the famous Rosenhan's (1973) study showed, patients were only allowed to leave when they agreed that they had a spoiled identity - that of a mentally ill person. In this sense, the institution which ascribes a stigmatizing label onto a person is the primary source of stigmatization.

We can now see that understanding self-stigma as a barrier for seeking treatment is paradoxical. From this perspective, the declared goal of combating self-stigma becomes the institutional form of reinforcing the institution's power of ascribing the stigma. The ascription of a psychiatric diagnosis is not just an ascription of any mental state (or a specific configuration of mental states and behaviors), but of one which is, by definition, pathological. This understanding does not question the stigmatizing status of being a mental health patient; it merely enhances the institution's power of transforming the self of treated individuals. They have to 
internalize the stigma of a diagnostic category, while rejecting the negative public opinions connected to the diagnosis (at the same time the opinions persist and the stigmatizing label is placed on patients by an institution acting on behalf of the public and in the public interest often disguised as patients' good). Even most mental health professionals hold very stigmatizing beliefs at a level similar to the general population (Babicki et al., 2021).

The paradoxical nature of anti-stigma campaigns can be better illustrated by the recently popular message of "It's OK not to be OK" used by many mental health awareness and antistigma campaigns (National Suicide Prevention Lifeline, 2016). The real message here seems to be: "it's OK not to be OK... as long as you seek treatment and do something to stop "being not OK". It's OK to be depressed, as long as you are acting responsibly and take care of yourself. If you notice other people "being not OK," you should offer support or refer them to a mental health professional, you shouldn't judge or blame them... as long as they are seeking professional help or take their medication. Otherwise you are entitled to call the police as involuntary treatment may be the only ethical solution (especially in the case of a perceived suicide risk or lack of treatment compliance in the case of serious mental disorders as bipolar or schizophrenia)."

Another contradiction is well exemplified by the recent case of the pop singer Britney Spears made popular by the \#FreeBritney campaign. The supposedly destigmatizing messages of her carers about her "medical condition" stress that she is unable to make decisions for herself (and therefore portray her as irresponsible or even less than fully human) because of her diagnosis of bipolar disorder. The understanding and compassionate attitude towards her disease is used as a justification for legal custody and total control over many aspects of her life, against her will.

In other words, the anti-stigma campaigns do not question the reality or validity of stigmatizing labels. They are only aimed at changing the attitude towards them in order to strengthen the legitimization and power of the labels, usually also constructing the subject as suffering from a chemical deficit requiring a pharmacological intervention (Fullagar, 2008).

\section{Biomedical model}

This legitimization is largely based on the assumption of a biological cause of mental health problems, which naturalizes and essentializes them. It assumes that mental disorders exist independently "out there" in reality and we merely discover them in nature, delineate them, more or less accurately, depending on the exact philosophical position taken (Karter, 2019), and subsequently, identify them in specific genetically predisposed subjects. The problem, then, is one of an abnormal biological constitution. In a blog post titled "We are Whole People, Not Broken Brains," Fisher (2013), a practicing psychiatrist who was diagnosed with schizophrenia, writes: "If you and the people around you believe that your mind will be defective and sick for the rest of your life, you are left without hope of ever having the agency to build a life. This dire prediction can become a self-fulfilling prophesy." A similar point is made by Scheff in his labeling theory (Scheff, 1966).

This is, however, the prevailing narrative about schizophrenia, most often portrayed as a "progressive brain disease" that requires life-long medication (Zipursky et al., 2013). Similarly, 
the popular view about depression created by the media and the pharmaceutical industry is that it is caused by a chemical imbalance in the brain, though there is little evidence for that (Lacasse \& Leo, 2005); on the contrary, a substantial body of evidence points to its psychological, cultural, social or economic causes and the effectiveness of non-pharmacological interventions (Stupak \& Dobroczyński, 2021). Though the official paradigm of psychiatry is usually described as a biopsychosocial one, Sharfstein (2005), as president of the American Psychiatric Association, gave an honest description of the actual situation: "we have allowed the biopsychosocial model to become the bio-bio-bio model". The biomedical message could be then interpreted as leading to self-stigma, even though it is not widely considered to consist of invalid stereotypes; in fact it is often promoted by anti-stigma campaigns which are also often funded, designed and promoted by psychiatric organizations and pharmaceutical companies (Kaczmarek, 2021).

In a review of experimental research and studies evaluating the impact of anti-stigma campaigns based on this "biomedical model," Longdon and Read (2017, p.28) write:

"While anti-stigma initiatives based on the <mental illness is an illness like any other> approach are well-intentioned, there is substantial evidence that they are not only ineffective but can actually increase attributions of dangerousness and desire for social distance". Importantly, they connect the failure of anti-stigma campaigns with an essentialist approach to mental health problems and review a set of studies showing that individuals who hold essentialist biases about various aspects of human diversity are more likely to demonstrate prejudicial perspectives. This is even more likely to occur when the "essence" in question is perceived in terms of inherent biological differences between the "normal" and the stigmatized. This basically dehumanizes mental health patients as sub-human faulty machines and provides a legal justification for forced treatment (Stupak \& Dyga, 2018).

The tension between essentialist and social constructionist approaches is well described by Hacking $(1999,2002)$. In order to escape the superficial distinction between treating medical diagnoses as referring to, on the one hand, something as real as planets or horses, and on the other merely social constructs, he proposes the notion of dynamic nominalism. This "making up people" thesis involves the distinction between "indifferent kinds" (e.g. quarks) and "interactive kinds" (e.g. children), i.e. quarks do not (probably...) react to our definitions of them, while the children do. This, according to Hacking, could reflect the difference between natural and social sciences. The typologies used are a product of the interaction between society, culture, science and administrative needs but at the same time they also constitute the subjects they classify. In this way they limit or expand potential possibilities of people who can now become an exemplar of a newly invented category; through a looping effect they change the way people think of themselves and behave because of the category assigned. This account fits well the self-stigmatization associated with the adoption of the biomedical narrative about mental distress. Patients adopting a more biomedical understanding of their distress are more self-stigmatizing and fare worse on different scales (Lipska, 2016), as if they felt they were powerless against and defined by their "broken brains". Staff empathy towards patients is also decreased by biomedical explanations of mental distress and may lead to dehumanization (Lebowitz \& Ahn, 2014). 


\section{Psychiatric discourse}

Moncrieff (2006) succinctly points to another aspect and shows how the biomedical model of mental distress provides a means of social control supporting neoliberal values, competitiveness and consumerism. Essentialist views on the nature of mental health problems imply that there is a desired "normal" state that can be achieved via consumption of drugs in order to rectify the condition of the brain.

However, instead of bringing resolution, people are not easily satisfied, as with material consumption. The need for medication only confirms their feelings of inferiority and anxiety. These feelings are debilitating and they help both to create the dissatisfaction that drives consumerist behaviour and to produce a state of mind that is necessary for an increasingly competitive working environment. A population that feels inadequate is more vulnerable to manipulation by advertising and less able to resist increasing demands from employers. (p. 301)

While Moncrieff (2006) is linking psychiatric discourse with economic relations (particularly neoliberalism), she is also describing the paradoxical situation of a person taking psychiatric drugs that resembles the paradox of stigma and anti-stigma campaigns. The drugs are supposed to eliminate the symptoms leading to taking drugs, but the act of taking drugs confirms one's diagnosis, and the diagnosis is the "proof" of being abnormal. Similarly, anti-stigma campaigns validate stigmatizing labels. It should be no surprise that gay-rights movements fought for depathologization of homosexuality, and not against the stigma of the "disease" through launching anti-stigma campaigns. Suggesting that homosexuality is a psychiatric disorder is now considered to be inappropriate and stigmatizing precisely because the label of a psychiatric disorder is stigmatizing by itself.

Cohen (2016, pp. 92-93) goes a bit further in presenting the wider context, showing that psychiatric ideas are now equaled to "common sense". A total institution and direct oppression is no longer needed; now patients and the general population embody the psychiatric discourse on a more voluntary basis. The discourse is internalized on the level of everybody's self-interpretations, whether or not they ever become patients as everyone is considered to be at risk of a psychiatric disorder. The expansion of the psy-professions helps to shape and govern a compliant and competitive population focused on correcting and improving their emotions for the sake of the neoliberal order. Individuals seek solutions to structural failings of the society through self-surveillance for symptoms of mental illness.

\section{Biopolitics}

This is the point where the concept of self-stigma becomes most apparent in its relation to Foucault's concepts of governmentality, panopticon and biopolitics or biopower. Of course, the dominating narrative concerning psychiatric disorders in general and stigma and selfstigma in particular needs to be understood in the context of Foucault's work on the relation of power and knowledge (and his understanding of discourse in general). As Foucault (1977) writes: 
We should admit...that power produces knowledge (and not simply by encouraging it because it serves power or by applying it because it is useful); that power and knowledge directly imply one another; that there is no power relation without the correlative constitution of a field of knowledge, nor any knowledge that does not presuppose and constitute at the same time power relations. (p. 27)

This discourse serves a specific societal role, shaping the subjectivities of patients, ex-patients and potential-patients and can be understood as a disciplinary tool. Internalized norms become a panopticon-like situation: "the inmates should be caught up in a power situation of which they are themselves the bearers." (Foucault, 1977, p. 201)

Recently there have even been calls to include data obtained from smartphones and Internet activity such as sensor data, speech and voice data, human-computer interaction, search history or social media posts to create "digital phenotypes" in order to screen for risk and improve diagnosis and treatment (Insel, 2018) which could be seen as a more concrete example of panopticon in this context.

Medicalization helps in turning this from a social or moral problem of privacy, freedom and equality into a medical one, or in turning the problem of the social norms embodied by diagnostic categories and ethical concerns about modifying and monitoring people's behavior into a moral problem of individual responsibility for living a healthy life, which makes it much easier to rationalize or justify in the context of the "public good" (Täuber, 2018). This brings to mind yet another boundary - the one between the mind and technology (Veerbek, 2009) that seems linked to the current debate surrounding digital surveillance in the context of the SARS-CoV-2 pandemic.

According to Cohen (2016), the medicalization of mental suffering resembles the ideology and interests of the ruling classes, but despite the title of his book (Psychiatric hegemony: A Marxist Theory of Mental Illness), theoretically he seems to rely mostly on Foucault (as is the case of critical psychiatry in general which also relies heavily on Goffman, Scheff, Laing and Szasz (Double, 2006)). In the Foucauldian tradition it could be also argued that we are dealing with something more "impersonal"; modern discourse on stigma and self-stigma can be seen as power that is, as Lemke (2002) says describing Foucault's idea of governmentality, "neither warlike nor juridical" (p. 52) and is exerted by forms of knowledge, strategies of power, and technologies of the self. Clearly, even if the Foucauldian perspective may seem insightful and appropriate theoretically, it fails to produce any kind of social change and even theoretically it may now seem to be a dead-end.

\section{Lukacs and reification}

A somewhat different account could come from the Frankfurt School which has long been regarded as the main Marxist tradition of philosophical and cultural critique. Lukacs' (1972) concept of reification has had a profound influence on this approach and on critical theory understood in a broader way, yet his work, for different reasons, became something of a classic (according to one definition, classic is what everyone knows, but nobody reads) represented mainly through negative accounts. However, the interest in Lukacs' writings has seen some revival after Axel Honneth's book on Reification (Feenberg, 2017). 
There are, of course, different contemporary interpretations of Lukacs' concept, but what interests me most here is Lukacs' (following Max Weber) observation that quantification and calculability underpins modern (capitalist) rationalization, which leads to a specific situation and construction of a subject and ultimately distorts reality or makes it unknowable (Jütten, 2010).

The simplest definition of reification is: "a relation between people [that] takes on the character of a thing and thus acquires a 'phantom objectivity"' (Lukacs, 1972, p. 83). As Jütten (2010, p. 236) mentions, this definition, however, "raises more questions than it answers." Pitkin (1987) identified over 20 meanings of reification, some of them in the text of History and Class Consciousness itself. Still, according to Jütten (2010), several main lines of thought could be distinguished: for Honneth and some other commentators, treating people (and oneself) as a thing is a core characteristic of reification, while other accounts stress the mediation of relationships between people by things or the fact that rationalized social institutions acquire such character.

Lukacs (1972, p. 87) distinguishes between objective and subjective aspects of reification:

Objectively a world of objects and relations between things springs into being (the world of commodities and their movements on the market). The laws governing these objects are indeed gradually discovered by man, but even so they confront him as invisible forces that generate their own power. The individual can use his knowledge of these laws to his own advantage, but he is not able to modify the process by his own activity. Subjectively - where the market economy has been fully developed - a man's activity becomes estranged from himself, it turns into a commodity which, subject to the non-human objectivity of the natural laws of society, must go its own way independently of man just like any consumer article.

In this short excerpt it is possible to see the basis for all of the interpretations mentioned above. In an essay tellingly called "Reification and the consciousness of the patient," Taussig (1980, p. 5) uses the example of a woman with a diagnosis of polymyositis (inflammation of many muscles) to make his point that, in the medical context, reification of diagnoses serves the "denial of authorship, the denial of relationship, and the denial of the reciprocity" that "produces grotesque mystifications," ultimately obscuring or hiding the social source and nature of the problems at hand and mistaking the appearance of social relations for their essence. While this is certainly important in the case of diseases and illnesses that can be "objectively" measured or assessed, their biological underpinning being relatively well understood, it seems that it is even more striking in the case of psychiatric disorders, which lack this characteristic. In the example provided by Taussig (1980), the diagnosis, especially considered in the context of power relationships (invoking, yet again, Foucault's perspective) and the authority of medical experts, leads to a deep alienation of the patient's self-understanding.

All of these different takes on reification may be relevant in the context of psychiatry (as a social institution), psychiatric diagnoses (that themselves resemble commodities or things and point to diseases or disorders treated as such), and the stigma and self-stigma of diagnosed people who may understand themselves as a specimen of a particular reified category and be treated as a commodity. What is more, the methodology of contemporary psychology and psychiatry as well as the way interventions are designed and implemented, and their success measured (also in case of anti-stigma campaigns), perfectly illustrate the remark that "the principle 
of rational mechanisation and calculability must embrace every aspect of life" (Lukacs, 1972, p. 91). The principle is at work not only with regards to what we instinctively recognize as commodities but also to postulated psychological and biological mechanisms in the context of psychiatric diagnoses and stigma. It could be considered to be the ultimate form of "reification of consciousness".

\section{Adorno and identity thinking}

As for Adorno, Mariotti (2009) gives a good summary of Adorno's stance on the role of psychiatry (exemplified by psychoanalysis) in post-war America. According to Adorno, psychoanalysis, despite its deep influence on critical theory, has in practice turned from a theoretical tool for analyzing bourgeois self-alienation into a part of a new regime of conventionalization and normalization seeking to subsume, homogenize, and categorize all that is other, different, or unique. It becomes part of the culture (and culture industry) of capitalism governed by the logic of commodity exchange.

This logic, as in Lukacs' account, is only superficially rational. "The irrationality of the rational system emerges in the psychology of its trapped subjects. The doctrine of rational behaviour leads into contradictions" (Adorno, 1967-8, n.p.). For Adorno this unsettling experience provides valuable insight into the non-identical, while the goal of psychiatry is to identify, classify and pathologize these experiences in the logic of identity thinking in order to control or eradicate them. Thus, psychoanalysis serves the status quo, eviscerating the qualitative variety of experience and imposing an abstract monotony on the administered world; it pushes people into conformity, instilling in them a self-canceling urge to be happy, normal, and popular (Mariotti, 2009).

Subsuming particular experiences under general categories redirects the cause of the problem away from society towards individual internal mechanisms, distressing experiences becoming a seemingly "normal" part of the discourse as domesticated and disarmed reified concepts or things. "Terror before the abyss" turns into an abstract, general, medicalized term apparently devoid of its political, social and cultural cause and context - anxiety (Adorno, 2005, p. 65). The details of an individual's history are reduced to mass-produced "goods", people's energy directed towards acquiring the right "fix", and subjects recreated as a composition of mechanical parts, an assemblage of objectified psychological mechanisms, instincts, biological impulses and inherited traits. The management of these parts is put under the collective authority of the society (Mariotti, 2009).

Infiltrated by and upholding mainstream values, psychoanalysis becomes a tool for calibrating individuals to work in conventional ways. As Adorno (1967-8, n. p.) puts it:

A technique intended to cure the instincts of their bourgeois distortions further subjects them to the distortions of emancipation. It trains those it encourages to champion their drives to become useful members of the destructive whole.

Abstracting from the peculiarities of psychoanalytical concepts and theories, it should be noted that most of the negative impact that Adorno attributes to psychoanalysis could be understood 
as a consequence of applying identity thinking in order to "cure" and control the human psyche, despite the fact that this distorts reality. Even if we were to disagree with Adorno's take on psychoanalysis, observing that there are different strands within psychoanalysis including those that are more critical of the social and cultural reality, this description would fit contemporary biomedical psychiatry even better, with its reliance on diagnostic categories. Contrasting dialectical and identarian thinking, Adorno wrote: "identarian thinking says what something comes under, what it exemplifies or represents, and what, accordingly, it is not itself" (Adorno 2007, p. 149).

As in Lukacs, bureaucracy, where individuals are assigned different classes or categories, is often considered to be a good example of such an approach. For the purpose of "knowing" and controlling, individuals become mere representatives of categories that they have been assigned to, while losing all qualitative differences and unique properties. This necessarily leads to misrepresentation of reality; subsuming specific phenomena under abstract and general categories creates an artificial relation of identity between objects, things (or people) that, although different, may be treated as being the same, equal (quantitatively) (Fagan, 2020; Feenberg, 2017).

Adorno was well aware that typologies or classifications can be used as negative identification machines used for labeling human beings, independent of their specific qualities, a fact he observed while witnessing the rise of Nazi psychology. That is why he insisted that The Authoritarian Personality should include a section on the ethics of applying such typologies (Oberle, 2018). In the context of the Holocaust, Bauman (1989) provided a similar account relying to a large degree on the Frankfurt School theorists. It should be noted that the first victims of mass exterminations in Nazi Germany were patients of psychiatric institutions, the technology of Holocaust was invented in psychiatric hospitals, and, perhaps, psychiatry as an institution, could be seen to foretell changes that would later be implemented in other societal contexts (in contemporary context, these could be, e.g. the digitalization and on-line provision of medical care or the use of similar techniques and surveillance for remote working).

Jütten (2010) notes that an account of reification should explain how it is possible that this phenomenon is present in everyday life without being recognized as a moral injury. As distressing (some, perhaps, would say: inadequate) as this comparison may be, in the case of the Holocaust as well as contemporary psychiatry and anti-stigma campaigns, the answer may lie in the ethical considerations associated with these actions; in both cases, a "greater good" (utilitarian or moral) is invoked and the people involved may believe that they are acting for a noble cause. The extermination of patients in Nazi Germany was justified both as a means of saving money for the economy (needed for the war effort) and as a merciful act of ending the suffering of those living a "life not worth living"; the labeling of contemporary patients and the biomedical logic behind anti-stigma campaigns are usually understood as beneficial for those affected. The experts "know better what is good" which is well exemplified by the special issue of World Psychiatry arguing for ignoring or amending the UN Convention on the Rights of Persons with Disabilities, the title of the editorial tellingly calling to "save the Convention from itself" (Appelbaum, 2019). 


\section{Concluding remarks}

By arguing that the biomedical model of mental health disorders is inherently stigmatizing, I have tried to show that anti-stigma campaigns, most often based on this essentializing approach, are in fact fueling stigmatization and self-stigmatization. Anti-stigma campaigns are set to produce subjectivities that could be understood in relation to Foucault's concepts of biopolitics, governmentality and panopticon. Similarly to Rose's (1979) account of eugenics, psychiatry seems to provide a solution for the "invisible threat" of a mental illness epidemic.

It seems that a return to the reflections of thinkers associated with the Frankfurt School could offer a surprisingly refreshing perspective for the study of contemporary psychiatry and stigmatization, placing them in differently conceptualized cultural and economic contexts. Many of the problems diagnosed as mental health disorders seem to stem from economic insecurity and inequalities (Smith, 2020; Wilkinson \& Pickett, 2018). Naturalizing, reifing and medicalizing people's problems justifies the prevalent economic and cultural order and prevents social change; even if they develop an alternative understanding of their distress, "irrational" patients are at least partially excluded from the public sphere where they could argue for a different approach. The "rational" ones repeat the biomedical narrative and thus see less need for change (Davis, 2020). Honneth's (1996) perspective and his account of recognition could be particularly promising in addressing this issue.

Hacking (2006, n.p.) provides an overview of how such typologies are produced in contemporary practice. He distinguishes ten "engines" ("1. Count! 2. Quantify! 3. Create Norms! 4. Correlate! 5. Medicalise! 6. Biologise! 7. Geneticise! 8. Normalise! 9. Bureaucratise! 10. Reclaim our identity!"). In the case of the $10^{\text {th }}$ engine (called "resistance" later on in the text) it is perhaps worth asking about the precise nature of the identity to be reclaimed and whether it is not similar to the one imposed. More importantly, while this strategy seems to be working relatively well for homosexuality, is it possible to present depression, bipolar disorder or schizophrenia not as a pathology (especially if we keep the existing labels)? It seems what could help here is only a radical change in conceptualizing these kinds of problems. There are already some attempts to use queer theory in the psychiatric context (LeFrançois \& Diamond, 2014) and this may produce interesting results.

Yet, the situation is more complicated than in the case of sexual preferences or gender identities as there are certainly people with psychiatric diagnoses that would genuinely benefit from organized help and support. Perhaps modeling the practice or understanding of mental health from the perspective of social services rather than medical interventions could be an avenue worth exploring. This would be in contrast to the prevailing attitude to stigma as something that can be eradicated by "educating people" about mental health conditions, or by training the stigmatized to better manage their stigmatizing labels. As Link \& Phelan (2001) suggest, changing both the discriminating beliefs and the power relations that allow stigmatizing may be crucial in combating stigma. The beliefs associated with stigmatizing labels could be invalidated by highlighting the superficially rational character of the labels themselves, adopting an approach stemming from the Frankfurt School perspective and applying negative dialectics. Most importantly, current approaches neglect questions about the social and political function of stigma as a form of power serving the status quo. In order to address this, the boundaries of these approaches to stigmatization need to be given more critical scrutiny. 


\section{References}

Adorno, T. (1967-8). Sociology and psychology. New Left Review 46, 67-80; 47, 79-97.

Adorno, T. (2005). Minima moralia: Reflections on a damaged life. Verso.

Adorno, T. (2007). Negative dialectics. Continuum.

Ahmedani, B. K. (2011). Mental Health Stigma: Society, Individuals, and the Profession. Journal of social work values and ethics, 8(2), 41-416.

Appelbaum, P. S. (2019). Saving the UN Convention on the Rights of Persons with Disabilities from itself. World Psychiatry, 18(1), 1-2. https://doi.org/10.1002/wps.20583

Bauman, Z. (1989). Modernity and the holocaust. Cornell University Press.

Babicki, M., Kotowicz, K., \& Mastalerz-Migas, A. (2021). The assessment of attitudes of medical doctors towards psychiatric patients-A cross-sectional online survey in poland. International Journal of Environmental Research and Public Health, 18(12), 6419. https://doi.org/10.3390/ ijerph18126419

Bathje G.J., Marston H.N. (2014). Self-Stigmatization. In: Teo T. (eds) Encyclopedia of Critical Psychology. Springer.

Bellack, A. S. (2006). Scientific and consumer models of recovery in schizophrenia: concordance, contrasts, and implications. Schizophrenia bulletin, 32(3), 432-442. doi:10.1093/schbul/sbj044

Cohen, B. (2016). Psychiatric hegemony: A Marxist Theory of Mental Illness. London: Palgrave.

Deacon, B. J. (2013). The biomedical model of mental disorder: A critical analysis of its validity, utility, and effects on psychotherapy research. Clinical Psychology Review, 33(7), 846-861. https://doi.org/10.1016/j.cpr.2012.09.007

Double, D. B. (Ed.). (2006). Critical psychiatry. Palgrave Macmillan UK. https://doi.org/10. $1057 / 9780230599192$

Dudley, J. R. (2000). Confronting stigma within the services system. Social Work, 45, 449-455.

Fagan, A. (2020, July 23). Theodor Adorno (1903-1969). Internet Encyclopedia of Philosophy. https://www.iep.utm.edu/adorno/

Feenberg, A. (2017). Why students of the Frankfurt School will have to read Lukács. In M. J. Thompson (Ed.), The Palgrave Handbook of Critical Theory (pp. 109-133). Palgrave Macmillan US. https://doi.org/10.1057/978-1-137-55801-5_6

Fisher, D. (2013, February 24). We are Whole People, Not Broken Brains. Mad in America. https://www.madinamerica.com/2013/02/we-are-whole-people-not-broken-brains/

Foucault, M. (1977). Discipline and Punish: The Birth of the Prison. London: Allen Lane.

Fullagar, S. (2008). Sites of Somatic Subjectivity: E-Scaped Mental Health Promotion and the Biopolitics of Depression. Social Theory and Health, 6(4), 323-341.

Goffman, E (1961). Asylums: Essays on the Social Situation of Mental Patients and

Other Inmates, New York, NY: Doubleday, Anchor Books 
Goffman, E. (1963). Stigma: Notes on the Management of Spoiled Identity. Englewood Cliffs, NJ: Prentice Hall.

Good, J. M. M. (2000). Disciplining social psychology: A case study of boundary relations in the history of the human sciences. Journal of the History of the Behavioral Sciences, 36(4), 383403.

Hacking, I. (1999). The social construction of what? Harvard University Press.

Hacking, I. (2002). Historical ontology. Harvard University Press.

Hacking, I. (2006, August 17). Making up people. London Review of Books, 28(16). https://www.lrb.co.uk/the-paper/v28/n16/ian-hacking/making-up-people

Honneth, A. (1995). The struggle for recognition: The moral grammar of social conflicts. MIT Press.

Insel T. R. (2018). Digital phenotyping: a global tool for psychiatry. World psychiatry : official journal of the World Psychiatric Association (WPA), 17(3), 276-277. doi:10.1002/wps.20550

Jütten, T. (2010). What is reification? A critique of Axel Honneth. Inquiry, 53(3), 235-256. https://doi.org/10.1080/00201741003784606

Kaczmarek, E. (2021). Promoting diseases to promote drugs: The role of the pharmaceutical industry in fostering good and bad medicalization. British Journal of Clinical Pharmacology, bcp.14835. https://doi.org/10.1111/bcp.14835

Karter, J. M. (2019). An ecological model for conceptual competence in psychiatric diagnosis. Journal of Humanistic Psychology, 002216781985248. https://doi.org/10.1177/0022167819852488

Lacasse, J. R., \& Leo, J. (2005). Serotonin and depression: a disconnect between the advertisements and the scientific literature. PLoS Medicine, 2, e392, doi: 10.1371/journal.pmed.0020392

LeFrançois, B. A., \& Diamond, S. (2014). Queering the sociology of diagnosis: Children and the constituting of 'mentally ill' subjects. Journal of Critical Anti-Oppressive Social Inquiry, 1(1), 39-61.

Lemke, T. (2002). Foucault, governmentality and critique. Rethinking Marxism, 14 (3),49-64.

Link, G., \& Phelan, C. (2001). Conceptualizing Stigma. Annual Review of Sociology, 27(1), 363385.

Lipska, A. (2016). Wplyw ukrytych przekonań na temat własnej diagnozy psychiatrycznej na autostygmatyzację, samowspótczucie, elastyczność psychologiczna oraz poczucie sensu życia. [M.A. Thesis, Szkoła Wyższa Psychologii Społecznej, Warszawa]. http://uczesieact.pl/wp-content/uploads/2018/04/Praca-magisterska-AnnaLipska.pdf

Longdon, E., \& Read, J. (2017). "People with problems, not patients with illnesses": Using psychosocial frameworks to reduce the stigma of psychosis. The Israel Journal of Psychiatry and Related Sciences, 54(1), 24-28.

Lukács, G. (1972). History and class consciousness: studies in Marxist dialectics. MIT Press.

Mariotti, S. (2009). Damaged life as exuberant vitality in america: Adorno, alienation, and the psychic economy. Telos, 2009(149), 169-190. https://doi.org/10.3817/1209149169 
Moncrieff, J. (2006). Psychiatric drug promotion and the politics of neo-liberalism. British Journal of Psychiatry, 188, 301-302.

National Suicide Prevention Lifeline (2016). It's OK not to be OK. https://youmatter.suicidepreventionlifeline.org/ok-not-ok/

Oberle, E. (2018). Theodor Adorno and the century of negative identity. Stanford University Press.

Pitkin, H. F. (1987). Rethinking reification. Theory and Society, 16(2), 263-293.

Rose, N. (1979). The psychological complex: mental measurement and social administration. Ideology and consciousness, 5, 5-68

Rosenhan, D. L. (1973). On being sane in insane places. Science, 179(4070), 250-258. https://doi.org/10.1126/science.179.4070.250

Scheff, T. (1966). Being Mentally Ill: A Sociological Theory. Aldine.

Sharfstein, S. S. (2005). Big Pharma and American Psychiatry: The Good, the Bad, and the Ugly. Psychiatric News. doi: 10.1176/pn.40.16.00400003

Smith, M. (2020, April 27). Universal basic income could improve the nation's mental health. The Conversation. http://theconversation.com/universal-basic-income-could-improve-the-nationsmental-health-123816

Stupak, R., \& Dobroczyński, B. (2021). From mental health industry to humane care. Suggestions for an alternative systemic approach to distress. International Journal of Environmental Research and Public Health, 18(12), 6625. https://doi.org/10.3390/ijerph18126625

Stupak, R., \& Dyga, K. (2018). Postpsychiatry and postmodern psychotherapy: Theoretical and ethical issues in mental health care in a Polish context. Theory \& Psychology, 28(6), 780-799. https://doi.org/10.1177/0959354318802973

Taussig, M. T. (1980). Reification and the consciousness of the patient. Social Science \& Medicine. Part B: Medical Anthropology, 14(1), 3-13. https://doi.org/10.1016/0160-7987(80)90035-6

Täuber, S. (2018). Moralized health-related persuasion undermines social cohesion. Front. Psychol. 9:909. doi: 10.3389/fpsyg.2018.00909

Tyler, I., \& Slater, T. (2018). Rethinking the sociology of stigma. The Sociological Review, 66(4), 721-743. https://doi.org/10.1177/0038026118777425

Wilkinson, R., \& Pickett, K. (2018). The Inner Level: How more equal societies reduce stress, restore sanity and improve everyone's well-being. Allen Lane.

Verbeek, P.-P. (2009). Ambient intelligence and persuasive technology: The blurring boundaries between human and technology. Nanoethics, 3(3), 231-242.

Zipursky, R. B., Reilly, T. J., \& Murray, R. M. (2013). The myth of schizophrenia as a progressive brain disease. Schizophrenia bulletin, 39(6), 1363-1372. doi:10.1093/schbul/sbs135 
Radosław Stupak holds an M.A. in Psychology. He is working towards a $\mathrm{PhD}$ in Psychology and towards a PhD in Philosophy at the Faculty of Philosophy of the Jagiellonian University. He is currently employed as a Teaching and Research Assistant at the Institute of Psychology of the Pedagogical University of Cracow. He is interested in a broad scope of questions related to contemporary approaches to mental health, philosophy and history of psychiatry and psychology, and the possibility of applying Critical Theory in this context. 